\title{
Nativity is associated with sugar-sweetened beverage and fast-food meal consumption among mexican-origin women in Texas border colonias
}

Joseph R Sharkey ${ }^{1 *}$, Cassandra M Johnson ${ }^{1,2}$ and Wesley R Dean ${ }^{1}$

\begin{abstract}
Background: Trends of increasing obesity are especially pronounced among Mexican-origin women. There is little understanding of dietary patterns among U.S.- and Mexico-born Mexican-origin individuals residing in newdestination immigrant communities in the United States, especially behaviors related to obesity, such as consumption of sugar-sweetened beverages (SSB) and fast-food meals (FFM).

Methods: The study used survey data of 599 adult Mexican-origin women from the 610 women who completed the 2009 Colonia Household and Community Food Resource Assessment (C-HCFRA), which was completed in person by trained promotora-researchers in 44 colonias near the Texas border towns of Progreso and La Feria. Data included demographic characteristics (age, education, nativity or country of birth, household income, household composition, and employment status), access to transportation, self-reported height and weight, food and nutrition assistance program participation, and consumption of SSB and FFM. Descriptive statistics were calculated by nativity (U.S.-born vs. Mexico-born); multivariable linear regression models were estimated for correlates of consumption of SSB and FFM.

Results: There are three major findings related to nativity. First, U.S.-born women consumed more SSB and FFM than Mexican-born counterparts in the same areas of colonias. Second, in the combined sample and controlling for other population characteristics, being born in Mexico was independently associated with FFM (fewer FFM), but not with SSB. Third, in analyses stratified by nativity, FFM and SSB were associated with each other among both nativity groups. Among Mexico-born women only, age, presence of a child, or being a lone parent was significantly associated with SSB; full-time employment, being a lone parent, and SSB consumption were each independently associated with increased frequency of FFM.

Conclusions: Our analyses revealed differences in prevalence and correlates of SSB and FFM based on country of birth. Nativity, as a proxy for acculturation, may indicate the extent that immigrants have adopted behaviors from their new environment. However, nativity could also indicate limited accessibility to resources such as food/ nutrition assistance programs, transportation, and proper documentation. Additionally, future research should focus on expanding our understanding of the meaning of nativity among individuals who share common contextual factors, but may have different life course experiences and resources needed to transition into a new place. Additional measures should be considered such as educational and occupational background, migration history, documentation status, and dietary acculturation, which may better explain heterogeneity within Hispanic subgroups.
\end{abstract}

\footnotetext{
* Correspondence: jrsharkey@srph.tamhsc.edu

'Program for Research in Nutrition and Health Disparities, School of Rural Public Health, Texas A\&M Health Science Center, College Station, TX (USA Full list of author information is available at the end of the article
} 


\section{Background}

Trends of increasing obesity are especially pronounced among Mexican-origin adults, who tend to be more overweight and obese than non-Hispanic white adults, especially Mexican-origin women who are one of the most obese populations in the U.S. $[1,2]$. This is of great concern for several reasons. First, since the 2000 U.S. Census, there has been a dramatic increase in the Hispanic or Latino population [3], primarily of Mexican origin [4]. Although much of this growth has occurred in traditional gateway locations such as Chicago, or the U. S. border with Mexico, nearly half of the U.S. population of Hispanics lives outside traditional gateway states [5]. Concentrations of Mexican immigration can be found in new destination immigrant settlements in the Midwest, the South, the Northeast, and the Northwest [5-11]. Second, obesity is related to other comorbidities including diabetes, which also is more common in Mexican-origin women than African American or non-Hispanic white women [12]. Third, there is little understanding of dietary patterns among Mexican-origin individuals in the United States, especially behaviors related to obesity [13-16], such as consumption of sugar-sweetened beverages (SSB) and fast-food meals (FFM) $[17,18]$.

In order to provide national guidance for an overall healthy diet, the 2010 Dietary Guidelines for Americans (DGA) includes a recommendation that individuals reduce intake of calories from added sugars and fats to maintain energy balance, meet nutrient requirements, and reduce risk for common chronic diseases including obesity and diabetes [19]. This recommendation provides motivation for understanding dietary behaviors associated with intake of these "empty calories", namely consumption of SSB and FFM [17,20-23]. Prior work also demonstrates the positive correlation between consumption of unhealthy beverages and unhealthy foods [24], and more specifically the consumption of SSB and FFM [25].

Research findings suggest that Mexican-origin adults, both U.S.- and foreign-born, may be more at risk for diet-related chronic diseases $[1,2,12,26-30]$ and obesogenic dietary behaviors including intake of SSB and FFM [13-16]. Among Mexican-origin adults, greater acculturation to foods and food patterns in the United States was associated with less-healthy dietary behaviors [31-34]. Acculturation is a multidimensional process affected by country of birth, age of arrival, years living in the United States, and contextual factors such as neighborhood composition, regional history of migration, and social networks [33,35-37]. However, there is a paucity of research devoted to understanding dietary behaviors relevant to chronic disease, such as SSB and FFM consumption among Mexican-origin immigrant women in the U.S, especially those living in areas that attract Mexican immigrants such as settlements or colonias in the border region between the U.S. and Mexico or the many new destination Mexican settlements spread throughout the U.S. [33,38-40]. In addition, the literature offers mixed findings regarding the influence of country of birth on health behaviors or health status [15,33,41-47]. Rather, most studies of this population of Mexican-origin women have focused on women's health (reproductive health, pregnancy, maternal and child health, birth outcomes and breast cancer) [6,42,48-54], intimate partner relationships including abuse $[55,56]$, substance abuse [57], stress/mental health [58-61], or focused on their children $[62,63]$. One recent study did find a greater degree of food insecurity among Mexicanborn women, compared with U.S.-born women in the same colonias [64]. Despite an increased risk for dietrelated chronic diseases, there are only a handful of studies that describe dietary patterns of Mexican-origin women $[16,27,39]$. Of these, one examined dietary habits to include FFM [40], and none focused on understanding both SSB and FFM consumption, particularly the extent of daily consumption of SSB and weekly frequency of FFM, or the factors associated with SSB and FFM among the hard-to-reach Mexican-origin families who reside in the growing colonias along the Texas border with Mexico. Research suggests that geographic location (greater access to convenience stores and fast food restaurants) [65-70], household composition (children in the home) [25], and individual or family characteristics (age, employment status, household resources) [25,71-74] were associated with unhealthy eating behaviors, such as SSB and FFM [75-78]. Considering that sociocultural, physical and economic elements of the environment may increase SSB and FFM, the purpose of this study was to examine data from face-to-face interviews conducted in Spanish by specially-trained promotora-researchers (indigenous community health workers trained in research methods) in 44 colonias along the Texas-Mexico border to: 1) compare demographic characteristics and eating behaviors between women born in the U.S. and women born in Mexico, all living in the same colonias and with similar spatial access to food resources, 2) examine the relation of demographic characteristics and eating behaviors to SSB and FFM, and 3) determine if the relationships differed based on nativity.

\section{Methods}

\section{Participants}

The study used survey data of 599 adult, Mexican-origin women from the 610 women who completed the 2009 Colonia Household and Community Food Resource Assessment (C-HCFRA), which was conducted in 44 
colonias near the Texas border towns of Progreso and La Feria and has been previously described [64]. Eleven women were excluded from analysis for missing data on daily consumption of SSB and/or weekly frequency of FFM.

\section{Data Collection}

Four promotora-researchers, who received special training, recruited participants door-to-door on weekdays and weekend days from September to October 2009, acquired informed consent, conducted face-to-face surveys in Spanish, and disbursed a modest incentive (\$5) at the completion of the survey. Details of the training of the promotora-researchers, recruitment of participants, and development and modification of the survey instrument to ensure semantic and conceptual equivalence and social and cultural appropriateness have been described elsewhere [64]. All data were collected in Spanish; all promotora-researchers were native Spanish speakers who also resided in nearby colonias.

\section{Measures}

Demographic characteristics included age, education, ethnic self-identification, marital status, nativity (country of birth), household composition (number of adults and children in the household), household income, and employment status. Federal poverty level (FPL) for 2009 was calculated from household income and composition data using 2009 Federal Poverty Guidelines [79]. Self-reported height and weight were used to calculate body mass index (BMI) in $\mathrm{kg} / \mathrm{m}^{2}$. Categories of BMI were constructed as normal $\left(<25 \mathrm{~kg} / \mathrm{m}^{2}\right)$, overweight $\left(25-29.9 \mathrm{~kg} / \mathrm{m}^{2}\right)$, and obese $\left(\geq 30 \mathrm{~kg} / \mathrm{m}^{2}\right)$. Access to transportation was assessed through car ownership, car availability, and source of transportation. Food and nutrition assistance programs included four federal programs: 1) Supplemental Nutrition Assistance Program (SNAP), 2) Women, Infants, and Children (WIC), 3) School Breakfast Program (SBP), and 4) National School Lunch Program (NSLP).

Eating behaviors were measured by self-reported daily servings of fruit and vegetables, SSB, and weekly frequency of FFM. To capture SSB and FFM consumption, participants were asked: "How many cans or glasses of regular soda (not diet) or sugar-sweetened beverages do you drink on an average day?" and "How many times a week do you eat fast food meals?" These measures were previously used in community-based work in North Carolina [80-82]. Two questions from a validated, selfreported two-item screener were combined to describe fruit and vegetable intake $[83,84]$.

\section{Statistical Analysis}

Release 11 of Stata Statistical Software (College Station, TX) was used for all statistical analyses; $p<0.05$ was considered statistically significant. Descriptive statistics were estimated for demographic characteristics, transportation, food and nutrition program participation, and eating behaviors. Comparisons were made between women who were born in the United States and in Mexico using $\chi^{2}$ test (categorical variables) and $t$-test (continuous variables). A conservative Bonferroni correction (alpha rejection region/number of tests to be conducted) was used to reduce Type I error rate for each individual test from 0.05 to 0.002 [85]. Bivariate correlations between SSB, FFM, and demographic characteristics, food and nutrition program participation, and eating behaviors were estimated. Separate linear regression models were estimated for the entire sample and stratified by nativity (U.S.-born and Mexico-born) to determine the association of independent variables with SSB and FFM. Statistically significant $(p<0.05)$ variables for demographic characteristics, transportation, food and nutrition program participation, and eating behaviors from the bivariate correlation estimations were simultaneously entered; backward elimination strategy was used, which sequentially removed statistically non-significant variables, to obtain the "best" set of independent variables [85]. Adjusted coefficients and standard errors (SE) are reported.

\section{Results}

Table 1 presents descriptive statistics for the entire sample and differences in proportions between women who were born in the United States $(32.4 \%, n=194)$ and those born in Mexico (67.6\%, $n=405)$. Compared with U.S.-born women, a greater proportion of Mexico-born women completed less than a $7^{\text {th }}$ grade education, reported a household income at or below $75 \%$ of the FPL, were married, had a greater number of children living in the household, were overweight, and did not have a car available. A greater proportion of U.S.-born women were employed full-time outside the home or were lone parents. Although similar proportions of U.S.and Mexico-born women reported no consumption of SSB (21.1\% of U.S.-born and 21.2\% of Mexico-born), U. S.-born women consumed a greater number of cans/ glasses of SSB each day (1.9 vs. 1.6); and among women who consumed at least one can/glass of SSB, U.S.-born women reported $2.4 \pm 1.9$ compared with $2.0 \pm 1.3$ for Mexico-born $(p=0.004)$. U.S.-born women also consumed more FFM each week (1.4 vs. 0.9); and among women who consumed $\geq 1 \mathrm{FFM}$ (72.7\% of U.S.-born vs. $64.9 \%$ of Mexico-born, $p=0.058$ ), U.S.-born women reported $2.0 \pm 1.4 \mathrm{FFMs} /$ week compared with $1.4 \pm 0.7$ for Mexico-born women $(p<0.001)$. Eight of the comparisons remained significant after adjusting for multiple comparisons with a revised level of statistical significance $(p \leq 0.002)$. In bivariate correlations (data not 
Table 1 Difference in Demographic Characteristics, Food and Nutrition Program Participation, and Eating Behaviors between U.S.-Born and Mexico-Born Mexican-origin Women in Texas-Mexico Border Colonias $(n=599)^{1}$

\begin{tabular}{|c|c|c|c|}
\hline & Total Sample $(n=599)$ & U.S.-born $(n=194)$ & Mexico-born $(n=405)$ \\
\hline Variable & $\%(n)$ & $\%(n)$ & $\%(n)$ \\
\hline \multicolumn{4}{|l|}{ Demographic characteristics } \\
\hline Age, y $($ mean $\pm S D)$ & $39.9 \pm 14.5$ & $38.1 \pm 14.7$ & $40.8 \pm 12.3^{*}$ \\
\hline \multicolumn{4}{|l|}{ Education } \\
\hline$<7^{\text {th }}$ grade & $30.2(181)$ & $10.8(21)$ & $39.5(160)^{* * * 2}$ \\
\hline $7^{\text {th }}-11^{\text {th }}$ grade & $31.5(189)$ & $24.7(48)$ & $34.8(141)^{* *}$ \\
\hline \multicolumn{4}{|l|}{ Ethnic self-identification } \\
\hline Hispanic & $9.2(55)$ & $19.6(38)$ & $4.2(17)^{* * * 2}$ \\
\hline Mexican American & $27.9(167)$ & $76.3(148)$ & $4.7(19)^{* * * 2}$ \\
\hline Mexican & $61.8(370)$ & $1.5(3)$ & $90.6(367)^{* * * 2}$ \\
\hline \multicolumn{4}{|l|}{ Household income (FPL) } \\
\hline No response & $25.4(152)$ & $26.8(52)$ & $24.7(100)$ \\
\hline$\leq 75 \% \mathrm{FPL}$ & $63.8(382)$ & $55.1(107)$ & $67.9(275)^{* * 2}$ \\
\hline 76\%-100\% FPL & $8.5(51)$ & $12.4(24)$ & $6.7(27)^{* *}$ \\
\hline \multicolumn{4}{|l|}{ Employment } \\
\hline Full-time outside home for wages & $26.7(160)$ & $33.5(65)$ & $23.5(95)^{* *}$ \\
\hline Part-time outside home & $21.4(128)$ & $19.1(37)$ & $22.5(91)$ \\
\hline \multicolumn{4}{|l|}{ Marital status } \\
\hline Married & $59.8(358)$ & $51.0(99)$ & $63.9(259)^{* *}$ \\
\hline \multicolumn{4}{|l|}{ Household composition } \\
\hline Adults (total) & $1.9 \pm 0.7$ & $1.9 \pm 0.8$ & $2.0 \pm 0.7$ \\
\hline Lone parent & 19.9 (119) & $27.8(54)$ & $16.0(65)^{* * * 2}$ \\
\hline Children (total) & $2.0 \pm 1.6$ & $1.7 \pm 1.4$ & $2.1 \pm 1.7^{* *}$ \\
\hline Children ( $\geq 1$ ) & $79.5(476)$ & $77.3(150)$ & 80.5 (326) \\
\hline Total adults and children & $3.9 \pm 1.8$ & $3.6 \pm 1.7$ & $4.1 \pm 1.9^{* *}$ \\
\hline \multicolumn{4}{|l|}{$\mathrm{BMI}\left(\mathrm{kg} / \mathrm{m}^{2}\right)^{3}$} \\
\hline Normal $(<25)$ & $30.3(177)$ & $35.1(67)$ & $28.0(110)$ \\
\hline Overweight (25-29.9) & $35.1(205)$ & $26.2(50)$ & $39.4(155)^{* * * 2}$ \\
\hline Obese $(\geq 30)$ & $34.6(202)$ & $38.7(74)$ & $32.6(128)$ \\
\hline \multicolumn{4}{|l|}{ Transportation } \\
\hline No car available & $19.5(117)$ & $11.9(23)$ & $23.2(94)^{* * * 2}$ \\
\hline Ride with family or friend ${ }^{4}$ & $88.9(104)$ & $91.3(21)$ & $88.3(83)$ \\
\hline Pay for transportation ${ }^{4}$ & $29.1(34)$ & $26.1(6)$ & $29.8(28)$ \\
\hline \multicolumn{4}{|l|}{ Food and nutrition program } \\
\hline SNAP & $55.1(330)$ & $55.7(108)$ & $54.8(222)$ \\
\hline$W I C^{5}$ & $42.6(203)$ & $42.7(64)$ & $42.6(139)$ \\
\hline School breakfast ${ }^{5}$ & $53.8(256)$ & $60.7(91)$ & $50.6(165)^{*}$ \\
\hline School lunch ${ }^{5}$ & $54.0(257)$ & $60.7(91)$ & $50.9(166)^{*}$ \\
\hline \multicolumn{4}{|l|}{ Eating behaviors } \\
\hline Fruit and vegetables/day & $3.5 \pm 1.6$ & $3.4 \pm 1.7$ & $3.5 \pm 1.5$ \\
\hline Sugar-sweetened beverages/day & $1.7 \pm 1.6$ & $1.9 \pm 2.0$ & $1.6 \pm 1.4^{* *}$ \\
\hline Fast food meals/week & $1.1 \pm 1.1$ & $1.4 \pm 1.5$ & $0.9 \pm 0.9^{* * * 2}$ \\
\hline
\end{tabular}

${ }^{1}$ Comparisons were performed using $\chi^{2}$ test (categorical variables) and $t$-test (continuous variables).

Statistically significant at level of: ${ }^{*} p<0.05 * * 0<0.01 * * * 0.001$

${ }^{2}$ Statistically significant after using Bonferroni correction for multiple comparison (Bonferroni-corrected $p=0.002$ ).

${ }^{3} n=585$ due to missing data on self-reported height or weight.

${ }^{4} n=117$ who do not have a car available

${ }^{5} n=476$ households with $\geq 1$ child 
shown), the following characteristics were significantly correlated with FFM and not with SSB: obesity $(r=-$ $0.13)$, full-time employment $(r=0.17)$, household income $>100 \%$ FPL $(r=0.18)$, number of children in the household $(r=-0.09)$, SNAP participant $(r=-$ $0.13)$, and not having a car available $(r=-0.08)$; other variables were correlated with both FFM and SSB. In addition SSB was correlated with FFM $(r=0.29, p<$ 0.001 ).

Adjusted linear regression estimates for the entire sample are shown in Table 2. Frequency of FFM and being a lone-parent household were independently associated with increased consumption of SSB; age and presence of at least one child were negatively associated with SSB. Being employed full-time and daily consumption of SSB were independently associated with increased frequency of FFM; age, receiving SNAP benefits, and being born in Mexico were associated with less frequent FFMs. In Table 3 nativity-stratified estimates for SSB indicate that increased frequency of FFM was independently associated with SSB among both U.S.and Mexico-born women. The influence of age, presence of a child, or being a lone parent was significant among Mexico-born women only. The correlates of increased frequency of FFM are shown in Table 4. For U.S.-born women, SNAP participation was associated with lower FFM and SSB consumption with greater FFMs; and among Mexico-born women, full-time employment, being a lone parent, and SSB consumption

Table 2 Association of Demographic Characteristics with Consumption of Sugar-Sweetened Beverages (SSB) and Frequency of Fast-Food Meals (FFM) among 599 Mexican-origin Women

\begin{tabular}{|c|c|c|}
\hline Variable & $\begin{array}{l}\text { SSB Consumption }{ }^{1} \\
\text { Coefficient (SE) }\end{array}$ & $\begin{array}{c}\text { FFM Consumption } \\
\text { Coefficient (SE) }\end{array}$ \\
\hline Mexico-born & $X$ & $-0.43(0.09)^{* * *}$ \\
\hline Age & $-0.02(0.01)^{* * *}$ & $-0.01(0.01)^{*}$ \\
\hline$\geq 1$ Child in household & $-0.45(0.18)^{* *}$ & X \\
\hline Lone parent household & $0.33(0.16)^{*}$ & $x$ \\
\hline Fast food meals/week & $0.36(0.06)^{* * *}$ & - \\
\hline SSB consumption/daily & - & $0.17(0.03)^{* * *}$ \\
\hline SNAP & $x$ & $-0.27(0.09)^{* *}$ \\
\hline Employed full-time & $x$ & $0.27(0.10)^{* *}$ \\
\hline Intercept & $2.44(0.31)^{* * *}$ & $1.40(0.18)^{* * *}$ \\
\hline Adjusted $R^{2}$ of model & 0.122 & 0.154 \\
\hline Significance of $\chi^{2}$ in model & $<0.0001$ & $<0.0001$ \\
\hline
\end{tabular}

${ }^{1}$ Dependent variable is consumption of regular soda or sugar-sweetened beverages (SSB) on an average day. All variables simultaneously entered; backward elimination of variables not statistically significant.

${ }^{2}$ Dependent variable is consumption of fast-food meals (FFM) during an average week. All variables simultaneously entered; backward elimination of variables not statistically significant.

$\mathrm{X}=$ dropped out of the model

Statistically significant at the level of: ${ }^{*} p<0.05{ }^{* *} p<0.01{ }^{* * *} p<0.001$
Table 3 Association of Demographic Characteristics and Frequency of Fast Food Meals (FFM) with Consumption of Sugar-Sweetened Beverages among 599 Mexicanorigin Women, by Country of Birth

\begin{tabular}{lcc}
\hline Variable & $\begin{array}{c}\text { U.S.-Born } \\
(\boldsymbol{n}=194) \\
\text { Coefficient (SE) }\end{array}$ & $\begin{array}{c}\text { Mexico-born } \\
(\boldsymbol{n}=\mathbf{4 0 5}) \\
\text { Coefficient (SE) }\end{array}$ \\
\hline Age & $-0.02(0.01)$ & $-0.02(0.01)^{* * *}$ \\
$\geq 1$ Child in household & $-0.01(0.36)$ & $-0.71(0.20)^{* * *}$ \\
Lone parent household & $0.22(0.31)$ & $0.42(0.19)^{*}$ \\
FFM consumption/week & $0.38(0.09)^{* * *}$ & $0.32(0.08)^{* * *}$ \\
\hline Intercept & $2.04(0.61)^{* * *}$ & $2.73(0.35)^{* * *}$ \\
Adjusted $R^{2}$ of model & 0.098 & 0.116 \\
Significance of $\chi^{2}$ in model & $<0.0001$ & $<0.0001$ \\
\hline
\end{tabular}

Dependent variable is consumption of regular soda or sugar-sweetened beverages on an average day. All variables simultaneously entered.

Statistically significant at the level of: ${ }^{*} p<0.05{ }^{* *} p<0.01{ }^{* * *} p<0.001$

were each independently associated with increased frequency of FFM.

\section{Discussion}

Although the incidence and prevalence of overweight and obesity have long reached critical levels and mirror increases in the consumption of SSB and FFM, especially among Hispanic adults and children, this is apparently the first study to examine the association of nativity with two less-healthy eating behaviors among Mexican women who reside in colonias along the Texas-Mexico border, where the population is primarily Mexican-origin and Spanish speaking individuals with similar spatial access to food stores and food service places [77]. Specifically, we examined the differences in SSB consumption and frequency of FFM between Mexican-origin women born in the United States and born in Mexico who were living in the same communities.

Table 4 Association of Demographic Characteristics with Weekly Consumption of Fast-Food Meals (FFM) among 599 Mexican-Origin Women, by Country of Birth

\begin{tabular}{lcc}
\hline Variable & $\begin{array}{c}\text { U.S.-Born } \\
(\boldsymbol{n}=\mathbf{1 9 4}) \\
\text { Coefficient (SE) }\end{array}$ & $\begin{array}{c}\text { Mexico-born } \\
(\boldsymbol{n}=\mathbf{4 0 5}) \\
\text { Coefficient (SE) }\end{array}$ \\
\hline Age & $-0.01(0.01)$ & $-0.01(0.01)$ \\
$\geq 1$ Child in household & $0.12(0.29)$ & $-0.10(0.13)$ \\
Lone parent household & $0.09(0.23)$ & $0.25(0.12)^{*}$ \\
SNAP & $-0.56(0.23)^{* *}$ & $-0.13(0.09)$ \\
Employed full-time & $0.27(0.23)$ & $0.26(0.10)^{* *}$ \\
SSB consumption/day & $0.22(0.05)^{* * *}$ & $0.11(0.03)^{* * *}$ \\
\hline Intercept & $1.47(0.48)^{* *}$ & $1.01(0.23)^{* * *}$ \\
Adjusted $R^{2}$ of model & 0.154 & 0.099 \\
Significance of $\chi^{2}$ in model & $<0.0001$ & $<0.0001$
\end{tabular}

Dependent variable is weekly consumption of fast-food meals (FFM). All variables simultaneously entered.

Statistically significant at the level of: ${ }^{*} p<0.05{ }^{* *} p<0.01{ }^{* * *} p<0.001$ 
This is also the first study that we are aware of that compared the influence of demographic characteristics on SSB and FFM consumption with Mexican-origin women born in the U.S. and in Mexico. There are three major findings related to nativity. First, U.S.-born women consumed more SSB and FFM than their Mexican-born counterparts. Second, in the combined sample and controlling for other population characteristics, being born in Mexico was independently associated with FFM (fewer FFM), but not with SSB. Third, in analyses stratified by nativity, FFM and SSB were associated with each other among both nativity groups. Possible reasons for observing an association between being born in Mexico and consuming fewer FFM include the higher proportion of Mexico-born with characteristics that represent lower socio-economic status, such as limited education, lower household income, employment status, and lack of transportation. The lack of association between nativity and SSB consumption may be explained by potentially distinct sources of SSB; U.S.born may consume more SSB as purchased soft drinks while Mexico-born women may rely on aguas frescas de frutas (homemade fruit-flavored waters with added sugars).

Although similar proportions of U.S.- and Mexicoborn Mexican women consumed at least one SSB each day or one FFM each week, U.S.-born women consumed a greater amount of SSB and greater number of FFM than their Mexico-born counterparts. Food and food habits have been linked to various measures of acculturation - single-item measures (e.g., country of birth or language), acculturation scores, and food-based assessments [86]. Although other studies have found years in the United States and language spoken to be associated with consumption of sugar beverages, this is apparently the first study to introduce the dimension of country of birth as an influence on SSB consumption [33], especially in the context of the predominantly Mexican-origin, Spanish language communities along the TexasMexico border. As previously mentioned, one study of San Francisco Bay Area Hispanic women documented a relationship between country of birth and fast-food consumption [40]. Notable demographic differences observed between Mexican women born in Mexico and those born in the U.S. suggests that country of birth may serve as a proxy measure for limited education, very low household income, being married, larger household composition, not having a car available during the day, and employment status outside the home. The results confirm prior reviews and research articles suggesting that less acculturation (e.g., country of birth) is associated with healthier diets $[33,34,87]$. This study is unique in that Hispanic subgroups (U.S.-born and Mexico-born) experience similar contextual exposures, such as density of Mexican population, colonia population characteristics, and locational access to food sources, which are considered a major influence on the acculturation process [33]. Stratified multiple variable regression analyses confirmed nativity differences and similarities in the influence of sample characteristics and eating behaviors on SSB and FFM consumption.

The observation of co-occurring unhealthy eating and drinking behaviors such as higher consumption of SSB and FFM has been reported previously [24,75]. Several studies document the association between both unhealthy dietary behaviors and adverse health incomes, including weight gain and obesity risk $[17,23]$, cardiometabolic risk [22,88,89], and type 2 diabetes [17]. This study adds to the paucity of research documenting SSB and FFM consumption among Mexican-origin women $[16,27,39]$, a population identified as at-risk for developing diet-related chronic-diseases [16,27]. At present, Mexican-origin women have the highest rates of obesity in the U.S. and in Mexico [1,2,26].

There are a number of strengths to this study. First, this is a large study of hard-to-reach Mexican women in border colonias. This population is of increasing national importance because such colonias can be considered an archetype for the new destination Mexican immigrant communities that are now found in great numbers throughout the continental U.S. Second, there are few studies describing dietary factors associated with obesity, including consumption of SSB and FFM among a sample of Mexican-origin women [16,27,39]. Previous studies with men and women of Mexican-origin have included at least one of these unhealthy dietary behaviors, but only in the context of general dietary patterns [13-15]. Understanding risk markers for obesity in Mexican-origin women is a major public health focus on both sides of the border and a bi-national priority $[5,7,19]$, which bolsters the importance of this study. A third strength is the identification of country of birth as a single-item measure of acculturation in a Mexican population, where Spanish is the predominant language.

There are several limitations to this study that warrant mention. First, the self-reported measures of SSB and FFM consumption may underreport actual frequency and amount consumed each day, which limits our ability to determine caloric intake from SSB or FFM. These measures of SSB and FFM, which did not identify a specific time frame, provided incomplete descriptions and did not specify culturally-appropriate SSB such as aguas frescas de frutas. As others have suggested, there is a need for specific prompts to better capture intakes of SSB and FFM $[25,69,90]$. Second, data were not available to describe seasonal variation in consumption of SSB and FFM. Third, data were not available to document type and amount of FFM consumed. Fourth, there were 
no additional measures of acculturation such as duration of residence in the U.S. Finally, the cross-sectional nature of this study prevents a temporal determination of predictors of consumption of SSB and FFM.

Despite these limitations, this research is highly relevant and timely given that the largest growing segment of the U.S. population is of Mexican origin and the concomitant increase in the number of new destination immigrant communities in interior and rural destinations including Iowa, North Carolina, and Tennessee $[6,7,9,91,92]$. Colonias are considered the archetype for new destination communities of Mexican-origin immigrants. Similar to new destination immigrant communities, colonias are smaller, more dispersed communities comprised of a disproportionately poor population of immigrants and their families with limited access to the kinds of resources necessary for facilitating economic and social mobility in a region characterized by adverse social conditions [9,93]. A distinguishing characteristic of colonias is that colonias are not "new" and now include both native and immigrant residents of Mexican-origin. Given consideration of the prototypical character of colonias, these findings have implications for dietitians developing interventions focused on the reduction of FF and SSB meals among Mexican-origin residents in rapidly growing new destination communities.

\section{Conclusions}

This study provides key findings on the importance of considering nativity in consumption of SSB and FFM. U.S.-born women consumed more SSB and FFM than Mexican-born counterparts in the same areas of colonias. Further, being born in Mexico was independently associated with consuming fewer FFM, but not associated with SSB. Finally, FFM and SSB were associated with each other among both nativity groups. Future research should focus on expanding our understanding of the meaning of nativity among individuals who share common contextual factors, but likely differ in life-course experiences and the resources needed to transition into a new place. Nativity may function as a proxy for acculturation and indicate the extent that immigrants adopt behaviors from their new environment. However, nativity could also indicate limited accessibility to resources such as food/nutrition assistance programs, transportation, and proper documentation. Additional measures should be considered such as educational and occupational background, resilience and access to a range of resources, migration history, documentation status, dietary acculturation, and lifecourse experiences, which may better explain heterogeneity in health outcomes among Hispanic subgroups $[92,93]$.

\section{Acknowledgements}

This research was supported in part with funding from the National Institutes of Health (NIH)/National Center on Minority Health and Health Disparities (\# 5P20MD002295) and by Cooperative Agreement \#1U48DP001924 from the Centers for Disease Control and Prevention (CDC), Prevention Research Centers Program through Core Research Project and Special Interest Project Nutrition and Obesity Policy Research and Evaluation Network. The content is solely the responsibility of the authors and does not necessarily represent the official views of the NIH and CDC. We thank Maria Davila and our promotora-researchers for data collection and the women who participated in the study.

\section{Author details}

${ }^{1}$ Program for Research in Nutrition and Health Disparities, School of Rural Public Health, Texas A\&M Health Science Center, College Station, TX (USA. ${ }^{2}$ UNC Center for Health Promotion and Disease Prevention and Department of Nutrition, UNC Gillings School of Global Public Health, Chapel Hill, NC (USA.

\section{Authors' contributions}

JRS developed the original idea for assessing sugar beverages and fast food. JRS worked on the development of the instrument and the protocol for collection of data. JRS, CMJ, and WRD wrote the first draft of the paper. JRS, CMJ, and WRD read and approved the final manuscript.

\section{Competing interests}

The authors declare that they have no competing interests.

Received: 6 August 2011 Accepted: 30 September 2011 Published: 30 September 2011

\section{References}

1. Ogden CL, Carroll MD: Prevalence of overweight, obesity, and extreme obesity among adults: United States, Trends 1976-1980 through 20072008. 2010 [http://www.cdc.gov/nchs/data/hestat/obesity_adult_07_08/ obesity_adult_07_08.pdf], [cited 201122 April].

2. Flegal KM, Carroll MD, Ogden $C L$, Curtin LR: Prevalence and trends in obesity among US adults, 1999-2008. JAMA 2010, 303(3):235-241.

3. Humes KR, Jones NA, Ramirez RR: Overview of Race and Hispanic Origin: 2010. U.S. Census Bureau; 2011

4. The Pew Hispanic Center: Country of Origin Profiles: Hispanics of Mexican Origin in the United States, 2008. 2011 [http://pewhispanic.org/files/ factsheets/59.pdf], 22 April 2010 [cited 20114 May].

5. Johnson KM, Lichter DT: Natural Increase: A New Source of Population Growth in Emerging Hispanic Destinations in the United States. Population and Development Review 2008, 34(2):327-346.

6. Bernosky de Flores $\mathrm{CH}$ : Human capital, resources, and healthy childbearing for Mexican women in a new destination immigrant community. Journal of Transcultural Nursing 2010, 21(4):332-341.

7. Zúñiga V, Hernández-León R: New Destinations: Mexican Immigration in the United States. New York: Russell Sage Foundation; 2006.

8. Gray VB, Cossman JS, Dodson WL, Byrd SH: Dietary acculturation of Hispanic immigrants in Mississippi. Salud pública de méxico 2005, 47(5):351-360.

9. Cornfield DB: Immigrant labor organizing in a "new destination city": approaches to the unionization of African, Asian, Latino, and Middle Eastern workers in Nashville. In Global Connections \& Local Receptions: New Latino Immigration to the Southeastern United States. Edited by: Ansley F, Shefner J. Knoxville, TN: University of Tennessee Press; 2009:279-297.

10. Jensen L: New Immigrant Settlements in Rural America: Problems, Prospects, and Policies. In Carsey Institute Reports on Rural America. Edited by: Duncan CM. Durham: University of New Hampshire; 2010:

11. Saenz R: The Changing Demography of Latinos in the Midwest. In Latinos in the Midwest. Edited by: Martinez RO. East Lansing: Michigan State University Press; 2011:33-56.

12. Phelan ST: Obesity in minority women: calories, commerce, and culture. Obstetrics and Gynecology Clinics of North America 2009, 36(2):379-392.

13. Flores M, Macias N, Rivera M, Lozada A, Barquera S, Rivera-Dommarco J, Tucker KL: Dietary patterns in Mexican adults are associated with risk of being overweight or obese. Journal of Nutrition 2010, 140(10):1869-1873. 
14. Carrera PM, Gao X, Tucker KL: A study of dietary patterns in the MexicanAmerican population and their association with obesity. Journal of the American Dietetic Association 2007, 107(10):1735-1742.

15. Duffey KJ, Gordon-Larsen P, Ayala GX, Popkin BM: Birthplace is associated with more adverse dietary profiles for US-born than for foreign-born Latino adults. Journal of Nutrition 2008, 138(12):2428-2435.

16. Winham DM, Florian TA: Hispanic women in EFNEP have low adherence with dietary guidelines regardless of acculturation level. Journal of Hunger \& Environmental Nutrition 2010, 5(4):498-509.

17. Malik VS, Popkin BM, Bray GA, Despres J-P, Hu FB: Sugar-sweetened beverages, obesity, type 2 diabetes mellitus, and cardiovascular disease risk. Circulation 2010, 121(11):1356-1364.

18. Bowman SA, Gortmaker SL, Ebbeling CB, Pereira MA, Ludwig DS: Effects of Fast-Food Consumption on Energy Intake and Diet Quality Among Children in a National Household Survey. Pediatrics 2004, 113:112-118.

19. U.S. Department of Agriculture and U.S. Department of Health and Human Services: Dietary Guidelines for Americans 2010 Washington, DC: U.S. Department of Agriculture, U.S. Department of Health and Human Services; 2010.

20. Bermudez Ol, Gao X: Greater consumption of sweetened beverages and added sugars is associated with obesity among US young adults. Annals of Nutrition \& Metabolism 2011, 57(3-4):211-218.

21. Malik V, Popkin B, Bray G, Després J, Willett W, Hu F: Sugar sweetened beverages and risk of metabolic syndrome and type 2 diabetes: a metaanalysis. Diabetes Care 2010, 33(1):2477-2483.

22. Duffey K, Gordon-Larsen P, Steffen LM, Jacobs DR, Popkin BM: Regular consumption from fast food establishments relative to other restaurants is differentially associated with metabolic outcomes in young adults. Journal of Nutrition 2009, 139(11):2113-2118.

23. Rosenheck R: Fast food consumption and increased caloric intake: a systematic review of a trajectory towards weight gain and obesity risk. Obesity Reviews 2008, 9(6):535-547.

24. Duffey KJ, Popkin BM: Adults with healthier dietary patterns have healthier beverage patterns. Journal of Nutrition 2006, 136(11):2901-2907.

25. Sharkey JR, Johnson CM, Dean WR: Less-healthy eating behaviors have a greater association with a high level of sugar-sweetened beverage consumption among rural adults than among urban adults. Food \& Nutrition Research 2011, 55:5819.

26. Rojas R, Aguilar-Salinas CA, Jiménez-Corona A, Shamah-Levy T, Rauda J, Ávila-Burgos L, Villalpando S, Lazcano Ponce E: Metabolic syndrome in Mexican adults: results from the National Health and Nutrition Survey 2006. Salud Publica de Mexico 2010, 52(Suppl 1):11-18.

27. Vella CA, Zubia RY, Ontiveros D, Cruz ML: Physical activity, cardiorespiratory fitness, and metabolic syndrome in young Mexican and Mexican-American women. Applied Physiology, Nutrition, and Metabolism 2009, 34(1):10-17.

28. Barquera S, Rivera JA, Espinosa-Montero J, Safdie M, Campirano F, Monterrubio EA: Energy and nutrient consumption in Mexican women 12-49 years of age: analysis of the National Nutrition Survey 1999. Salud Publica de Mexico 2004, 45(Suppl 4):S530-S539.

29. Sundquist J, Winkleby M: Country of birth, acculturation status and abdominal obesity in a national sample of Mexican-American women and men. International Journal of Epidemiology 2000, 29(3):470-477.

30. Wang Y, Beydoun MA: The obesity epidemic in the United Statesgender, age, socioeconomic, racial/ethnic, and geographic characteristics: a systematic review and meta-regression analysis. Epidemiologic Reviews 2007, 29(1):6-28.

31. Benavides-Vaello S: Cultural influences on the dietary practices of Mexican Americans: a review of the literature. Hispanic Health Care International 2005, 3:27-35.

32. Perez-Escamilla R, Putnik P: The role of acculturation in nutrition, lifestyle, and incidence of type 2 diabetes among Latinos. Journal of Nutrition 2007, 137:860-870

33. Ayala GX, Baquero B, Klinger S: A systematic review of the relationship between acculturation and diet among Latinos in the United States: Implications for future research. Journal of the American Dietetic Association 2008, 108(8):1330-1344.

34. Dixon LB, Sundquist J, Winkleby M: Differences in Energy, Nutrient, and Food Intakes in a US Sample of Mexican-American Women and Men: Findings from the Third National health and Nutrition Examination Survey, 1988-1994. Am J Epidemiol 2000, 152:548-57.
35. Van Hook J, Glick JE: Immigrant and living arrangements: moving beyond economic need versus acculturation. Demography 2007, 44:225-249.

36. Ellis $M$, Wright R: Spatial demography special feature: Assimilation and differences between the settlement patterns of individual immigrants and immigrant households. Proc Natl Acad Sci 2005, 102:15325-15330.

37. Viruell-Fuentes EA: Beyond acculturation: Immigration, discrimination, and health research among Mexicans in the United States. Social Science \& Medicine 2007, 65:1524-1535.

38. Benavides-Vaello S, Brown SA: Evaluating guiding questions for an ethnographic study of Mexican American women with diabetes. Hispanic Health Care International 2010, 8(2):77-84.

39. Espinosa de los Monteros K, Gallo LC, Elder JP, Talavera GA: Individual and area-based indicators of acculturation and the metabolic syndrome among low-income Mexican American women living in a border region. American Journal of Public Health 2008, 98(11):1979-1986.

40. Norman S, Castro C, Albright C, King A: Comparing acculturation models in evaluating dietary habits among low-income Hispanic women. Ethn Dis 2004, 14:399-404.

41. Montoya J, Salinas J, Barroso C, Mitchell-Bennett L, Reininger B: Nativity and nutritional behaviors in the Mexican origin population living in the US-Mexico border region. Journal of Immigrant and Minority Health 2010, 13(1):94-100.

42. Wingo PA, Kulkarni A, Borrud LG, McDonald JA, Villalobos SA, Green DC: Health disparities among Mexican American women aged 15-44 years: National Health and Nutrition Examination Survey, 1999-2004. Am J Public Health 2009, 99(7):8.

43. Sussner K, Lindsay A, Greaney M, Peterson K: The influence of immigrant status and acculturation on the development of overweight in Latino families: a qualitative study. Journal of Immigrant \& Minority Health 2008, 10(6):497-505.

44. Mier N, Ory MG, Zhan D, Conkling M, Sharkey JR: Health-related quality of life among Mexican Americans living in colonias at the Texas-Mexico border. Social Science \& Medicine 2008, 66(8):1760-1771.

45. Yeh M-C, Viladrich A, Bruning N, Rye C: Determinants of Latina obesity in the United States: the role of selective acculturation. Journal of Transcultural Nursing 2009, 20(1):105-115.

46. Carter-Pokras O, Zambrana R, Yankelvich G, Estrada M, Castillo-Salgado C, Ortega A: Health status of Mexican-origin persons: do proxy measures of acculturation advance our understanding of health disparities? Journal of Immigrant and Minority Health 2008, 10(6):475-488.

47. Dinh K, Castro F, Tein J-Y, Kim S: Cultural predictors of physical and mental health status among Mexican American women: a mediation model. American Journal of Community Psychology 2009, 43(1):35-48.

48. Thiel de Bocanegra H, Trinh-Shevrin C, Herrera A, Gany F: Mexican immigrant male knowledge and support toward breast and cervical cancer screening. Journal of Immigrant and Minority Health 2009, 11(4):326-333.

49. Wilson EK: Differences in contraceptive use across generations of migration among women of Mexican origin. Maternal and Child Health Journal 2009, 13(5):641-651.

50. Campesino M, Ruiz E, Glover JU, Koithan M: Counternarratives of Mexicanorigin women with breast cancer. Advances in Nursing Science 2009, 32(2): E57-E67.

51. Osypuk TL, Bates LM, Acevedo-Garcia D: Another Mexican birthweight paradox? the role of residential enclaves and neighborhood poverty in the birthweight of Mexican-origin infants. Social Science \& Medicine 2010 70(4):550-560.

52. Johnson MA, Marchi KS: Segmented assimilation theory and perinatal health disparities among women of Mexican descent. Social Science \& Medicine 2009, 69(1):101-109.

53. Nuño T, Martinez M, Harris R, García F: A promotora-administered group education intervention to promote breast and cervical cancer screening in a rural community along the U.S.-Mexico border: a randomized controlled trial. Cancer Causes and Control 2011, 22(3):367-374.

54. Ceballos M, Palloni A: Maternal and infant health of Mexican immigrants in the USA: the effects of acculturation, duration, and selective return migration. Ethnicity \& Health 2010, 15(4):377-396.

55. Liendo NM, Wardell DW, Engebretson J, Reininger BM: Victimization and revictimization among women of Mexican descent. Journal of Obstetric, Gynecologic, \& Neonatal Nursing 2011, 40(2):206-214. 
56. Grzywacz JG, Rao P, Gentry A, Marín A, Arcury TA: Acculturation and conflict in Mexican immigrants' intimate partnerships: the role of women's labor force participation. Violence Against Women 2009 15(10):1194-1212.

57. Caetano R, Ramisetty-Mikler S, Wallisch LS, McGrath C, Spence RT: Acculturation, drinking, and alcohol abuse and dependence among Hispanics in the Texas-Mexico border. Alcoholism: Clinical and Experimental Research 2008, 32(2):314-321.

58. Shattell MM, Smith KM, Quinlan-Colwell A, Villalba JA: Factors contributing to depression in Latinas of Mexican origin residing in the United States: implications for nurses. Journal of the American Psychiatric Nurses Association 2008, 14(3):193-204.

59. Kaestner R, Pearson JA, Keene D, Geronimus AT: Stress, allostatic load, and health of Mexican immigrants. Social Science Quarterly 2009, 90(5):1089-1111

60. Flores E, Tschann JM, Dimas JM, Bachen EA, Pasch LA, de Groat CL: Perceived discrimination, perceived stress, and mental and physical health among Mexican-origin adults. Hispanic Journal of Behavioral Sciences 2008, 30(4):401-424.

61. Hatchett BR, Garcia CC, Williams L: Mexican-American women in the colonias: effects of cultural and environmental stressors. Journal of Borderland Studies 2002, 17(2):79-96.

62. Reifsnider E, Flores Vela A, Beckman Mendez D, Nguyen H, Keller C, Dowdal Smith S: Perceptions of children's body sizes among mothers living on the Texas Mexico border (La Frontera). Public Health Nursing 2006, 23(6):488-495

63. Bayles B: Perceptions of childhood obesity on the Texas-Mexico border. Public Health Nursing 2010, 27(4):320-328.

64. Sharkey JR, Dean WR, Johnson CM: Association of household and community characteristics with adult and child food insecurity among Mexican-origin households in colonias along the Texas-Mexico Border. International Journal for Equity in Health 2011, 10:19.

65. Drewnowski A: Obesity and the food environment: Dietary energy density and diet costs. American Journal of Preventive Medicine 2004, 27(3):154-162.

66. Creel JS, Sharkey JR, McIntosh WA, Anding J, Huber JC: Availability of Healthier Options in Traditional and Nontraditional Rural Fast-Food Outlets. BMC Public Health 2008, 8:395.

67. Sharkey JR, Horel S: Neighborhood Socioeconomic Deprivation and Minority Composition Are Associated with Better Potential Spatial Access to the Food Environment in a Large Rural Area. J Nutr 2008, 138:620-627.

68. Sharkey JR, Horel S, Han DK, Huber JC: Association between neighborhood need and spatial access to food stores and fast food restaurants in neighborhoods of Colonias. International Journal of Health Geographics 2009, 8(1):9.

69. Sharkey JR, Johnson CM, Dean WR, Horel S: Focusing on fast food restaurants alone underestimates the relationship between neighborhood deprivation and exposure to fast food in a large rural area. Nutrition Journal 2011, 10(1):10.

70. Fleischhacker SE, Evenson KR, Rodriguez DA, Ammerman AS: A systematic review of fast food access studies. Obesity Reviews 2011, 12(5):e460-e471.

71. Bleich SN, Wang YC, Wang Y, Gortmaker SL: Increasing consumption of sugar-sweetened beverages among US adults: 1988-1994 to 1999-2004. The American Journal of Clinical Nutrition 2009, 89(1):372.

72. Duffey KJ, Gordon-Larsen P, Steffen LM, Jacobs DR, Popkin BM: Drinking caloric beverages increases the risk of adverse cardiometabolic outcomes in the Coronary Artery Risk Development in Young Adults (CARDIA) Study. The American Journal of Clinical Nutrition 2010, 92(4):954.

73. Rehm CD, Matte TD, Van Wye G, Young C, Frieden TR: Demographic and behavioral factors associated with daily sugar-sweetened soda consumption in New York City adults. Journal of Urban Health 2008, 85(3):375-385.

74. Kuczmarski MF, Mason MMA, Schwenk MEA, Evans MK, Zonderman AB: Beverage Consumption Patterns of a Low-Income Population. Topics in Clinical Nutrition 2010, 25(3):191.

75. Sharkey JR, Johnson CM, Dean WR: Less-healthy eating behaviors have a greater association with a high level of sugar-sweetened beverage consumption among rural adults than among urban adults. Food and Nutrition Research 2011, 55(5819):9.
76. Sharkey JR, Johnson CM, Dean WR, Horel SA: Focusing on fast food restaurants alone underestimates exposure to fast food in a large rural area. Nutrition Journal 2011, 10(10):14

77. Sharkey JR, Horel S, Han D, Huber J: Association between neighborhood need and spatial access to food stores and fast food restaurants in neighborhoods of colonias. International Journal of Health Geographics 2009, 8(1):9.

78. Sharkey JR, Johnson CM, Dean WR: Association between proximity to and coverage of traditional fast-food restaurants and non-traditional fastfood outlets and fast-food consumption among rural adults. International Journal of Health Geographics 2011, 10:37.

79. U.S. Department of Health and Human Services: The 2009 HHS Poverty Guidelines [http://aspe.hhs.gov/poverty/09poverty.shtml].

80. Johnson CM, Sharkey JR, Dean WR: Eating Behaviors and Social Capital are Associated with Fruit and Vegetable Intake among Rural Adults. Journal of Hunger and Environmental Nutrition 2010, 5(3):302-315.

81. Sharkey JR, Branch LG, Zohoori N, Giuliani C, Busby-Whitehead J, Haines PS: Inadequate nutrient intake among homebound older persons in the community and its correlation with individual characteristics and healthrelated factors. Am J Clin Nutr 2002, 76:1435-45.

82. North Carolina Prevention Partners: Healthy Eating: Starting the Conversation.[http://www.ncpreventionpartners.org/dnn/].

83. Resnicow K, Odom E, Wang T, Dudley W, Mitchell D, Vaughan R, Jackson A, Baranowski $T$ : Validation of three food frequency questionnaires and 24hour recalls with serum carotenoid levels in a sample of African American adults. Am J Epidemio/ 2000, 152(11):1072-80.

84. Campbell M, Carr C, Devellis B, Switzer B, Biddle A, Amamoo M, Walsh Zhou B, Sandler R: A randomized trial of tailoring and motivational interviewing to promote fruit and vegetable consumption for cancer prevention and control. Ann Behav Med 2009, 38(2):71-85.

85. Kleinbaum DG, Kupper LW, Muller KE, Nizam A: Applied Regression Analysis and Other Multivariate Models. Pacific Grove: Duxbury Press; 1998.

86. Satia-Abouta J, Patterson RE, Neuhouser ML, Elder J: Dietary acculturation: Applications to nutrition research and dietetics. J Am Diet Assoc 2002, 102:1105-1118.

87. Romero-Gwynn E, Gwynn D: Dietary Patterns and Acculturation Among Latinos of Mexican Descent. JSRI Research report \#23 East Lansing, MI: The Julian Samora Research Institute; 1997.

88. Duffey KJ, Gordon-Larsen P, Steffen LM, Jacobs DR, Popkin BM: Drinking caloric beverages increases the risk of adverse cardiometabolic outcomes in the Coronary Artery Risk Development in Young Adults (CARDIA) Study. American Journal of Clinical Nutrition 2010, 92(4):954-959.

89. Fung TT, Malik V, Rexrode KM, Manson JE, Willett WC, Hu FB: Sweetened beverage consumption and risk of coronary heart disease in women. The American Journal of Clinical Nutrition 2009, 89(4):1037-1042.

90. Popkin BM, Armstrong LE, Bray GM, Caballero B, Frei B, Willett WC: A new proposed guidance system for beverage consumption in the United States. Am J Clin Nutr 2006, 83:529-42.

91. Gray VB, Cossman JS, Dodson WL, Byrd SH: Dietary acculturation of Hispanic immigrants in Mississippi. Salud Publica Mex 2005, 47:351-360.

92. Marrow HB: New Destination Dreaming: Immigration, Race, and Legal Status in the Rural American South. Standford, California: Stanford University Press; 2011.

93. Gallo LC, Penedo FJ, Espinosa de los Monteros K, Arguelles W: Resiliency in the face of disadvantage: do Hispanic cultural characteristics protect health outcomes? Journal of Personality 2009, 77(6):1707-1746.

doi:10.1186/1475-2891-10-101

Cite this article as: Sharkey et al:: Nativity is associated with sugarsweetened beverage and fast-food meal consumption among mexicanorigin women in Texas border colonias. Nutrition Journal 2011 10:101. 